\title{
EL SILENCIOSO ABANDONO DE LA FORMACIÓN DEL
}

\author{
EDUCADOR/A INTEGRAL (1)
}

The quiet abandonment of the comprehensive educator's training

O silencioso abandono da formação do educador completo

\section{Christian Miranda Jaña}

Universidad de Chile. Fono: +56 2978773. Correo electrónico:

christian.miranda@u.uchile.cl

(1) Texto que recoge enseñanzas y reflexiones generadas en diálogos con el filósofo español Vicente Serrano (Universidad Austral de Chile) y las estudiantes de la Carrera de Educación Parvularia y Básica Inicial (Universidad de Chile). Forma parte del proyecto FONDECYT 1140827 financiado por CONICYT-Chile.

\section{Resumen}

La calidad de la formación docente se ha constituido en una preocupación central de los sistemas educativos contemporáneos. Sin embargo, la falta de claridad respecto de lo que constituye la naturaleza de lo pedagógico propiamente tal dificulta que las políticas educativas se orienten en una dirección clara y planificada. En este sentido el presente artículo reflexiona respecto de los desafíos y peligros que asechan a profesión docente y propone un decálogo de principios que podrían constituir un desarrollo profesional docente integral que rescate el legado del pensamiento educativo y fortalezca el plus de la pedagogía.

Palabras Clave: profesión docente; pensamiento pedagógico; decálogo

\begin{abstract}
:
The quality of teacher education has become a central concern of contemporary educational systems. However, the lack of clarity on what constitutes the nature of the pedagogical properly so difficult that educational policies are oriented in a clear and planned direction. In this sense this article reflects on the challenges and dangers that lie in wait to teaching profession and discusses a Decalogue of principles that could be a comprehensive teacher professional development to rescue the legacy of educational thought and strengthen the plus of pedagogy.
\end{abstract}

Keywords: teaching profession; pedagogical thought; decalogue 


\section{Resumo}

A qualidade da formação de professores tornou-se uma preocupação central dos sistemas educativos contemporâneos. No entanto, a falta de clareza sobre o que constitui a natureza do pedagógico adequada tão difícil que as políticas educativas são orientadas em uma direção clara e planejadas. Nesse sentido, este artigo reflete sobre os desafios e perigos que estão à espera para ensinar profissão e propõe uma lista de princípios que poderiam formar um desenvolvimento profissional de professores abrangente para resgatar o legado do pensamento educacional e fortalecer o plus de pedagogia.

Palavras-chave: profissão de ensino; pensamento educacional; decálogo. 
En el debate actual sobre la profesión docente es importante reflexionar académicamente en torno a la propuesta del Gobierno y los desafíos que plantea a la formación de educadores, y cuando se trata además de un sistema de desarrollo profesional, es relevante detenerse a analizar sus fundamentos, nudos críticos y desafíos, con el fin de contribuir a relevar sus voces y experiencias educativas, esa reflexión y análisis deben ir acompañados no sólo de las posibilidades, sino también de los desafíos de tan compleja tarea. En efecto, tal como nos adelanta Esteve (2005):

\footnotetext{
"la profesión docente es siempre una actividad ambivalente. Nos presenta, como el mito de Jano - el de dos caras- una puerta abierta por la que podemos entrar y salir. Por una parte, la enseñanza puede vivirse con optimismo, y convertirse en una forma de autorrealización profesional, ya que en ella podemos darle sentido a toda una vida. Por otra, no es posible esconder la otra cara de la tarea docente: una profesión exigente, a veces físicamente agotadora, sujeta siempre al juicio de un público que con sus preguntas la pone a prueba, no solo en los conocimientos, sino también en la propia coherencia personal".
}

En el marco anterior, nos aproximaremos al develamiento de esas "dos caras" desde la historia del pensamiento pedagógico y su estrecha relación con la formación docente.

La Pedagogía tal como la conocemos -ligada histórica y teóricamente con la filosofía-surge en Grecia. Para Platón, no solo la preservación de la especie humana se logra mediante la transmisión de saberes como el fuego, la habilidad mecánica y el uso de un lenguaje, sino que también proyectando lo que los mismos griegos llamaron Paideia, es decir, el proceso educativo encaminado a formar buenos ciudadanos, seres morales y dotados de habilidades intelectuales de modo integral y que comenzó por preguntarse acerca de la posibilidad misma de enseñar aquello que era lo más preciado en la Polis: la virtud, entendida como la excelencia del hombre en su condición de tal. No es de extrañar, por ello, que el legado de Platón haya sido considerado en su conjunto como un gran tratado de pedagogía o que obra culminante del pensamiento griego -La Política- fuera escrita por el filósofo Aristóteles, maestro de Alejandro Magno, desde su más temprana edad.

Esa visión de la enseñanza no cambió mucho en el mundo romano, en otros aspectos avanza a través del Humanitas la formación de virtudes personales como la 
autoridad, la amistad, la dignidad, la prudencia y virtudes públicas como la confianza, la justicia y la felicidad que son importantes de recordar en este debate.

Posteriormente, durante la denominada Edad Media, estos preceptos no cambiaron tanto, pero dieron un giro desde el maestro como centro de la enseñanza hacia los saberes o artes liberales, expresadas en el dominio de la elocuencia (Trivium) y las matemáticas (Quadrivium).

Si bien este legado de virtudes y saberes no mutaron mucho en el mundo moderno, en otros aspectos da un giro copernicano que es importante recordar en esta reflexión, tal como nos señala Ortega y Gaset (2001) a propósito del aporte de la Pedagogía al pensamiento contemporáneo:

\footnotetext{
“En la enseñanza -y más en general en la Educación- hay tres términos: lo que habría que enseñar - o el saber-, el que enseña -o maestro- y el que aprende -o discípulo-. Pues bien, con inconcebible obcecación, la enseñanza partía del saber y/o del maestro. El discípulo, el aprendiz, no era principio de la pedagogía. La innovación de Rousseau y sus sucesores fue simplemente trasladar el fundamento de la ciencia pedagógica del saber y del maestro al discípulo y reconocer que es éste y sus condiciones peculiares lo único que puede guiarnos para construir un organismo con la enseñanza”, o una carrera, como diríamos hoy.
}

En consonancia con ello, Lessing (1982) un destacado pensador alemán de la Ilustración, a fines de siglo XVIII, escribe "La Educación del Género Humano". Es de este texto y de las premisas pedagógicas que sistematiza del que deriva en gran medida el concepto mismo de Educación y el de Bildung entendido como Formación Integral, y que tan estrecha relación guarda con el pensamiento griego, romano y medieval referidos con anterioridad.

Desde un punto de vista más contemporáneo, el pensador francés Lyotard (2006), en respuesta a una pregunta que le hacía el Consejo de Universidades de Quebec (Canadá), publicó “La condición Posmoderna". En ésta, donde reflexiona sobre el saber en las culturas occidentales, sostiene que las transformaciones que se estaban produciendo a finales del siglo XX en éste y en sus modos de producción inciden directamente en la Educación y en la Enseñanza. Obra de repercusión inmediata y que en lo que concierne a la reflexión de hoy, resulta decisiva, precisamente porque en ella se afirmaba que el conocimiento se había transformado radicalmente y con él la Educación y la Enseñanza, convertidos en simples mercancías por la tecnocracia 
moderna, Performance o -ritos de la escolarización-, desnaturalización ésta que le llevaba a declarar la muerte de la Educación entendida como Bildung, es decir, de esa formación integral que ha inspirado a las Escuelas de Pedagogía, fisurando la imagen de la dignidad misma del proceso educativo entendido como un derecho humano, sustraído de la dinámica pura y dura de los mercados. Allí, en el mismo libro de Lyotard puede leerse algo tan actual a los fines de este análisis como lo siguiente:

"La pregunta, explícita o no, planteada por el estudiante, por el Estado o por la institución de enseñanza, ya no es: ¿es eso verdad?, sino ¿para qué sirve? En el contexto de la mercantilización del saber, esta última pregunta, las más de las veces, significa: ¿se puede vender? Y, en el contexto de argumentación del poder: ¿es eficaz? Pues la disposición de una competencia educativa en las condiciones descritas pareciera que debiera tener como resultado el ser vendible y ser eficaz por definición”.

Es decir, principios como la justicia, la verdad y el aprendizaje para todos, propios del perfil identitario de los educadores, por no ser eficaces ni vendibles pasan a ser elementos silenciosamente abandonados.

Pero esta idea, esta reflexión realizada hace 35 años y que reconocemos como parte de nuestro presente ¿significa en verdad el fin de la educación integral de nuestros educadores y maestros? ¿O significa más bien sólo uno de esos desafíos que deben enfrentar nuestros docentes al momento de someterse a los dictámenes de las reformas educativas tan en boga? Ese es el dilema que quisiera proponerles como hilo conductor que nos permita a todos reflexionar una vez más sobre la Educación y la Enseñanza, en el marco de la crisis actual del sistema educacional.

Y para reflexionar sobre ello quisiera regresar a este Auditórium y a la actual coyuntura educacional, al análisis del Proyecto de Ley que crea el Sistema de Desarrollo Profesional Docente, al que de algún modo estamos contribuyendo, porque todo análisis posibilita develar las convergencias y divergencias en las que está en juego el rezago, estancamiento o progreso educativo, un alcance académico que de algún modo intenta revelar lo implícito en una dinámica de contrapuntos que busca develar aspectos que de otro modo permanecen ocultos. Como todo análisis, es asumido como una práctica comunicativa provisional, parcial y siempre inconclusa, que como tal involucra un punto de vista temporal, discutible y controversial. Pero, así descrito, todo análisis es una aproximación del proceso educativo mismo, o más bien, todo proceso comunicativo 
busca convertirse en un acto educativo, pues tal como plantea el Sabio oriental Krishamurti (2009): "el educador, aspira comunicar a sus aprendices los saberes que los tornen virtuosos e integrales y, porque no decirlo, felices”. Esa aspiración, es lo que creo, anhelamos todos aquellos que entendemos la importancia de la Educación y la Enseñanza.

El Sistema de Desarrollo Profesional Docente, al igual que el Mito de Jano presenta dos caras, una de fortalecimiento y contribución a la Enseñanza y la dignidad del maestro como lo son las medidas de derogación del Artículo 46 de la Ley General de Educación que abría una puerta a profesionales no-pedagogos a ejercer la docencia, desde el supuesto que el saber disciplinar de alta calidad lleva en sí la capacidad de enseñarlo. En este mismo sentido, es relevante el intento de asumir el acompañamiento del profesor novel, mediante un sistema de inserción profesional consistente con las mejores prácticas de formación docente en el mundo. No obstante, el proyecto presenta la "otra cara", una que habla de reformas compensatorias -basadas en lógicas de acción verticalistas del "deber ser" y teorías del déficit- y no de progresos pedagógicosbasados en lógicas de acción participativas, del "poder ser” y teorías del desarrollo- que a continuación se enuncian:

a) Fundamentos. Mientras el progreso educativo ${ }^{1}$ se funda en evidencias científicas y saberes pedagógico-disciplinares el proyecto se sustenta en elementos económicos y tecnocráticos.

b) Formación. Mientras el progreso educativo se sustenta en la teoría del desarrollo profesional colaborativo el proyecto habla desde una lógica de formación compensatoria.

c) Evaluación. Mientras el progreso educativo se sustenta en criterios de evaluación y retroalimentación entre pares el proyecto habla de mediciones individuales y pruebas estandarizadas.

d) Profesionalidad. Mientras el progreso educativo se funda en dotar de mayor autonomía, pasión y compromiso el proyecto habla de regulación, incentivo y liderazgo.

\footnotetext{
${ }^{1}$ El progreso educativo se refiere a la evidencia científica producto de la investigación educacional. 
e) Aprendizaje. Mientras el progreso busca establecer la conexión entre la formación y el aprendizaje de niños y niñas el proyecto habla de la enseñanza, estándares de desempeño y eficacia escolar.

Y si he introducido esta breve consideración en torno a la actual coyuntura y las posibilidades que nos presenta el análisis aquí desarrollado, es porque guarda una estrecha relación con el silencioso abandono del que hemos sido causa y parte, lo que debe llevarnos a analizar la actual crisis del sistema educativo. Y no nos referimos sólo a los problemas urgentes e inmediatos que acaparan portadas de los diarios o molestan a la opinión pública, como los resultados del SIMCE, sino también a ese otro problema no menos urgente, tal vez el mismo, que tiene que ver con la sociedad en que vivimos, y que Lyotard ya esbozaba en su recordada obra, la de una sociedad que ha abandonado o está en trance de hacerlo, el viejo ideal del Bildung, de la formación integral que forjó la pedagogía y que releva el progreso educativo que anhelamos. En una crisis como está, la Enseñanza y la Educación, y su transformación, se convierten en el mejor de los casos en dos productos más del mercado educacional, la primera, en un incentivo a la competividad, el individualismo y el asilamiento y, la segunda, en una respuesta a demandas que enfatizan áreas curriculares privilegiadas en los sistemas de medición educacional, es decir, en una pieza más del engranaje del mercado.

Lyotard vincula esa transformación, la que creemos vivimos hoy, a lo que él llama la pérdida en la fe de los grandes relatos. Para ello establecía una diferencia en cuanto al saber, y a sus modos de enseñarlo. A diferencia de la ciencia positiva, lo que él llama la enseñanza integral involucra no sólo cumplir con estándares de desempeño eficaces e incentivos económicos a quienes rindan exitosamente pruebas, algo que en el Proyecto de Carrera Docente es cabalmente considerado, sino también prácticas de colaboración, actitudes éticas y estéticas, en suma, un conjunto que legitima el saber docente y a la vez sirve de lazo social entre el educador, el niño/a y sus familias. Pero un saber de estas características, una Carrera Docente para un saber como este, que trasciende las meras destrezas eficaces e incentivos de mercado, ha sido, a mi juicio, silenciosamente olvidado en la actual propuesta legislativa, tal vez por representar un exceso, un colorido innecesario que, estoy seguro, valoramos cada uno de los aquí presentes, de acuerdo a nuestra experiencia vital. 
Es ese excedente, ese colorido vital, sobre lo que descansa la clave de la crisis descrita por Lyotard y, entonces, lo que está en juego en nuestra sociedad, es la pérdida de ese plus que forjó la Polis griega, que fomentó la Pedagogía Moderna y que a su vez ha relevado el progreso científico de la investigación educativa por espacio de 50 años, y que por extensión debería ser un sello ineludible en las propuestas sobre Carrera Docente.

Pues bien, para dar un paso más en esta reflexión académica, proponemos acudir a la noción capital del pensamiento de Freire, desarrollada en su obra Pedagogía de la Autonomía, subtitulada saberes necesarios para la práctica educativa y que se vincula como pocas a ese excedente: la palabra maestro. Vocablo, que se use en español para designar a dos actores relevantes en el proceso educativo. Es un maestro, aquel del que aprenden -y aprendemos todos-, y que se sitúa más allá de las aulas, iluminando y orientando nuestras vidas. Él o ella, que con su obrar formativo, hace de este mundo un lugar mejor para vivir. En la otra acepción, se utiliza para designar la tarea profesional de educar desde la más temprana edad.

Es el maestro/a, en su sentido más preciso el que no enseña para una prueba o materia específica, sino que nos introduce en todas ellas, ofreciéndonos una educación integral, razón por la cual una de sus tareas fundamentales consiste en enseñar a aprender. Sobre ello, cabe preguntarse ¿Cuál es el rasgo que permite aplicar la mis ma noción, el de maestro, al máximo referente de nuestras vidas y aquella que lo es por antonomasia, el profesor de primaria? Creo que ese rasgo que permite encontrar la coincidencia y la analogía precisa entre ambos es aquel plus que Lyotard considera amenazado o la armonía existencial y "vital" que caracteriza a la maestra de Diotima (2004) y que permite distinguir, entre ser un profesional calculador o un educador creativo. Para la Formación docente, lo que está en juego es su identidad pedagógica. Es hacer presente que la calidad del educador/a es más que la certificación en el dominio del curriculum escolar o las rúbricas que presente en su portafolio pedagógico. Lo propio y común del maestro, es convertir su docencia en una tarea social que cuide el desarrollo de las virtudes sociales, personales, de los afectos, de la cooperación con sus colegas y con las familias: es favorecer comunidad. Al respecto, se puede observar el abandono silencioso -falta de debate y develamiento- de parte importante de este legado pedagógico en el Sistema de Desarrollo Profesional Propuesto, constituyéndose dos de 
los desafíos mayores al que se debe hacer frente: El distanciamiento y la frialdad en la tarea educativa.

Una reflexión que emerge antes de concluir y que consideramos importante de reflexionar es: ¿Cómo pasar de Sistema de Desarrollo Profesional a un Sistema Integral de Desarrollo Profesional que responda al legado, identidad y necesidades de los maestros y maestras de nuestro país?

Sin ser una respuesta, proponemos a docentes de nuestras instituciones educacionales un Decálogo de Compromisos Pedagógicos que, aunque limitados o limitantes, buscan ser una contribución a mejorar su calidad de vida e identidad, a saber: IDENTIFÍCATE con los principios y legado de la pedagogía sobre excelencia, calidad, equidad, responsabilidad ética e integralidad, pues ellos constituyen el sello que caracteriza a los educadores.

ASUME LA RESPONSABILIDAD de creer y propagar los valores que la pedagogía posee y otorgan identidad a sus educadores, en especial aquellos que se relacionan con el conocimiento disciplinar, el saber pedagógico, la subjetividad y respeto por el otro.

DEDÍCATE a la docencia; ella implica consagrar muchas veces tiempo personal y familiar a labores de creación, desarrollo y evaluación de aprendizajes estudiantiles.

HAZ DE LA ALEGRÍA una característica del quehacer docente, pues no debes olvidar que una tarea central de tu trabajo se orienta a mostrar lo maravilloso que es el mundo.

ESCUCHA a tus estudiantes, comunidad y familia considerando sus ritmos y formas de ser en el mundo, pues del apoyo de ellos depende en gran medida el éxito de tu vida y trabajo.

RESPETA el carácter inacabado del educando y consagra los principios de indeterminación, diversidad e inclusión como ejes centrales de tu actuación con y en el mundo.

TEN FE en que cada estudiante que guíes en su proceso de aprendizaje, posee el potencial y el valor suficiente para lograr sus metas, independientemente de su condición, social, económica y religiosa. 
SÉ PACIENTE con tus estudiantes; ellos y ellas poseen sus propios ritmos de aprendizaje; espera, pues tu misión central es facilitar las condiciones para la construcción de conocimientos, habilidades y actitudes, y para ello se requiere tiempo y esmero.

FÓRMATE PERMANENTEMENTE en los planos espiritual, humano y profesional, pues si hay algo que caracteriza a la labor educativa es su constante emergencia y creación, dada la dinámica de cambio que caracteriza al ethos docente.

VALORA TU PROFESIÓN ya que ella es una de las más importantes de la sociedad y si un hijo o hija te dice el día de mañana:"quiero ser educador", no te enojes ni deprimas, pues significa que dejaste huella con tu trabajo, en los que más quieres: tu propia descendencia.

En síntesis, percibimos que las propuestas del Gobierno son un avance, pero que desatienden elementos centrales que la Pedagogía ha forjado desde sus inicios y que serían cruciales en la resolución de la crisis de sentido y legitimidad que afecta al sistema propuesto. Al respecto es prioritario mantener estos espacios de reflexión, análisis y propuestas entre estudiantes, educadores y académicos, asumiendo como premisa que para un desarrollo profesional de largo aliento se debe escuchar las voces de los maestros y maestras, pasando desde una lógica centrada en hablar de reformas a una de progresos educativos, incentivar el valor de la pedagogía desde valores que consagren el compromiso educativo y fijando el Desarrollo Profesional Docente como política de Estado y no del Gobierno de turno.

\section{Referencias bibliográficas}

Diotima (2004). El perfume de La maestra. En el laboratorio de la vida cotidiana. Icaria Editorial: Barcelona.

Esteve, J. (2004): El Malestar Docente. Paidos: Barcelona.

Freire, P. (2006). Pedagogía de la Autonomía. Saberes necesarios para la práctica educativa. Siglo XXI: México D.F.

Krishamurti, J. (2009). Sobre la Educación. Kairos: Barcelona.

Lessing, G. (1982). La Educación del género Humano. Editora Nacional: Madrid. 
Lyotard, J. (2006). La condición Postmoderna. Informe sobre el saber. Cátedra: Madrid.

Ortega y Gaset, J. (2001). Misión de la Universidad. UBA:Buenos Aires. 